\title{
Gloria Nielfa CRISTÓBAL (dir.), Mujeres en los Gobiernos
} locales. Alcaldesas y concejalas en la España contemporánea

Madrid, Biblioteca nueva, 2015, 263 p.

Danièle Bussy Genevois

\section{(Q) OpenEdition}

\section{Journals}

Édition électronique

URL : http://journals.openedition.org/clio/13132

DOI : 10.4000/clio.13132

ISSN : $1777-5299$

Éditeur

Belin

Édition imprimée

Date de publication : 1 juin 2016

Pagination : 310-313

ISBN : 978-2-7011-9852-1

ISSN : 1252-7017

\section{Référence électronique}

Danièle Bussy Genevois, « Gloria Nielfa cristóbal (dir.), Mujeres en los Gobiernos locales. Alcaldesas y concejalas en la España contemporánea », Clio. Femmes, Genre, Histoire [En ligne], 43 | 2016, mis en ligne le 25 août 2016, consulté le 23 septembre 2020. URL : http://journals.openedition.org/clio/13132 : DOI : https://doi.org/10.4000/clio.13132

Ce document a été généré automatiquement le 23 septembre 2020

Tous droits réservés 


\title{
Gloria Nielfa CRISTÓBAL (dir.), Mujeres en los Gobiernos locales. Alcaldesas y concejalas en la España contemporánea
}

\author{
Madrid, Biblioteca nueva, 2015, 263 p.
}

Danièle Bussy Genevois

\section{RÉFÉRENCE}

Gloria Nielfa Cristóbal (dir.), Mujeres en los Gobiernos locales. Alcaldesas y concejalas en la

España contemporánea, Madrid, Biblioteca nueva, 2015, 263 p.

1 Une recherche pluridisciplinaire originale et extrêmement précise, consacrée aux «Femmes dans les municipalités; maires et conseillères municipales en Espagne contemporaine " vient de paraître sous la direction de Gloria Nielfa, professeure et historienne du contemporain et du genre de l'Université Complutense de Madrid, dont les recherches font autorité.

2 L'ambition est claire : recueillir toute la documentation existante, quelle qu'en soit la forme, privée ou publique (témoignages des actrices ou de leurs successeurs, correspondances, presse, archives municipales non détruites pendant la guerre civile...) afin de faire émerger du silence de l'histoire les femmes ayant exercé des fonctions municipales, de la fin du XIX ${ }^{e}$ siècle à aujourd'hui. Remarquons que le choix a été fait de s'intéresser à la totalité des régions et aux villages autant qu'aux villes importantes, autre façon de ne pas privilégier des « cas » déjà connus de célébrités.

3 L'intérêt de l'étude, dont cette longue durée est un indice, réside dans le caractère pluridisciplinaire de l'entreprise, dans sa construction et sa mise en pratique : ce sont, en effet, cinq historiennes, trois géographes et une juriste, qui définissent l'objet commun, l'analysent en fonction de leur discipline et rédigent à plusieurs mains. Par ailleurs, l'ouvrage s'inscrit dans un champ peu exploré en dépit des remarquables avancées de l'histoire des femmes et du genre en Espagne, celui du rôle des Espagnoles 
dans l'administration, dans un contexte gouvernemental en perpétuel changement; seuls les travaux pionniers de Gloria Franco Rubio, consacrés plus particulièrement à la période franquiste, avaient apporté, en 1981 et 1982, des éléments-clés sur le sens et les limites de leur rôle.

L'organisation de l'ouvrage se fait autour de sept grands chapitres correspondant à la complexe chronologie gouvernementale de l'Espagne contemporaine: ce choix entraîne évidemment un certain déséquilibre des chapitres dû au nombre inégal de femmes concernées à chacune de ces périodes, et aux difficultés de la documentation. Cette segmentation rend indispensable une bonne contextualisation, obligation à laquelle se soumettent évidemment les rédactrices: on regrette cependant que les précisions historiques n'interviennent parfois qu'en cours de chapitre et non clairement au début, choix surprenant dans un ouvrage très pédagogique par ailleurs.

Dans une belle introduction, Gloria Nielfa définit les modalités de la participation des Espagnoles - ou de leur soumission - en régime monarchique, dictatorial ou démocratique : la théorisation emprunte non seulement aux historiennes espagnoles et à leur volonté de repenser les concepts de "démocratie", d'"égalité » ou de « citoyenneté » (Mary Nash, Carmen Molinaro, Rosa Capel, Ana Aguado, entre autres), mais aussi aux Européennes (Gisela Bock, Geneviève Fraisse...) et aux NordAméricaines, notamment Carole Pateman ou Karen Offen, dont les ouvrages ont été diffusés en Espagne avec une grande antériorité sur la France (C. Pateman a été traduite dès 1995, pour ne prendre que cet exemple).

6 Marta del Moral Vargas présente les passionnants débats sur les capacités féminines à exercer des tâches professionnelles, qui se sont déroulés depuis la fin du xix $x^{e}$ siècle jusqu'aux années vingt, sous la Monarchie d'Alphonse XIII, dans un moment aux prises à la fois avec les revendications du catholicisme social, du mouvement ouvrier naissant et de l'ébauche d'une pensée féministe. La dictature du général Primo de Rivera (1923-1930) est analysée par la même chercheuse et par Guadalupe Gómez-Ferrer ; les femmes étudiées ont été nommées par le dictateur, mais l'ambigüité de leur statut et de leurs capacités d'action donne lieu à une intéressante mise au point.

7 Il est clair que le passage du pays en république après une dictature qui a signifié la dernière tentative du roi pour se maintenir au pouvoir est un des chapitres attendus de cet ouvrage, rédigé par Gloria Nielfa et Rosario Ruiz Franco. La constitutionnalisation, en 1931, de l'égalité des sexes et du vote des femmes, en même temps que la réforme de la législation locale, permet aux femmes de remplir des fonctions de gestion municipale dans de nouvelles conditions; les auteures en ébauchent la typologie en soulignant le rôle des institutrices et des militantes de partis, majoritairement républicaines mais aussi de droite, héritières de la dictature. Autre apport des gouvernements républicains socialistes, l'autonomie de la Catalogne permet de nuancer les possibilités offertes aux femmes en fonction des politiques différentes selon le territoire. Au plan national, le retour au pouvoir des conservateurs en 1934-1935 entraîne d'ailleurs la destitution de nombreuses femmes socialistes ou radicales, certains villages devenant déjà lieu d'affrontements. Les portraits, nombreux et presque tous neufs, sont particulièrement nourris d'archives et souvent remarquables.

8 Avec le coup d'État de juillet 1936 contre le Front populaire élu en février de la même année, nombre de femmes maires socialistes seront exécutées par les franquistes dès les premières semaines, comme María Domínguez, "première maire » d'un village en Aragon. La guerre civile et ses lourdes conséquences sur la répression et l'exil sont donc 
analysées en lien avec la République et aussi une actualité plus récente, le travail politique sur la mémoire effectué en Espagne depuis la loi de 2007. En effet, chaque chapitre donne lieu à des pages de conclusions, particulièrement intéressantes quant à l'examen de l'échec de la remarquable tentative démocratique de 1931-1939.

Gloria Nielfa, cette fois-ci en collaboration avec l'historienne M. del Carmen Muñoz Ruiz, analyse les freins imposés par le franquisme et le poids de la Phalange féminine sur les possibilités pour les femmes d'exercer des responsabilités. Leur étude corrobore l'importance de la Loi de 1961 autorisant le travail féminin dans certaines limites; elles détectent l'existence de quelques femmes au niveau municipal; ce n'est cependant qu'en 1967 qu'une femme devient maire d'une capitale de province, Bilbao: Pilar Careaga qui avait été la première femme ingénieure à la fin des années vingt achève ainsi un long parcours au service des extrêmes-droites.

Quant aux chapitres sur la Transition démocratique (deux pour mieux permettre une analyse en finesse), ils bénéficient des apports, pour l'étude de la Constitution de 1978, de la juriste Magdalena Suárez Ojeda, et des deux géographes Juana Rodríguez Moya et Cándida Gago qui dressent la cartographie de la distribution territoriale des charges municipales assurées par des femmes.

11 Si l'ouvrage a une rédaction souvent descriptive, il est clairement indispensable à la connaissance de citoyennes, inconnues pour la plupart, et modifie en profondeur l'histoire administrative et du genre. Bonne bibliographie, extrême minutie de la recherche, clarté des tableaux et des cartes, portraits émouvants : autant d'apports à une facette complémentaire de l'histoire politique de l'Espagne contemporaine.

\section{AUTEURS}

\section{DANIĖLE BUSSY GENEVOIS}

Université Paris 8

EA 4385 